\title{
Comparative Study of Z N Staining vs. Flurochrome Staining and Impact of Sample Processing on Diagnosis of Tuberculosis from Various Clinical Samples
}

\author{
Yogita Mistry¹, Sangita Rajdev², Summaiya Mullan² \\ ${ }^{1}$ TB-IRL Laboratory, Government Medical College, Surat, India \\ ${ }^{2}$ Department of Microbiology, Government Medical College, Surat, India \\ Email: dryogitamistry@gmail.com
}

How to cite this paper: Mistry, Y., Rajdev, S. and Mullan, S. (2016) Comparative Study of Z N Staining vs. Flurochrome Staining and Impact of Sample Processing on Diagnosis of Tuberculosis from Various Clinical Samples. Advances in Microbiology, 6, 953958.

http://dx.doi.org/10.4236/aim.2016.613089

Received: October 2, 2016

Accepted: November 18, 2016

Published: November 21, 2016

Copyright (c) 2016 by authors and Scientific Research Publishing Inc. This work is licensed under the Creative Commons Attribution International License (CC BY 4.0).

http://creativecommons.org/licenses/by/4.0/

\begin{abstract}
Background: Tuberculosis is a highly infectious disease and India has the highest burden with it. Diagnosis of tuberculosis in many countries is still dependent on microscopy. Although its sensitivity is low in comparison to culture and molecular methods, its sensitivity can still be improved by using fluorescence staining method and processing of samples by homogenization and concentration method. Material and methods: Samples were collected from all newly registered suspected cases of tuberculosis in tertiary care hospital from outward and indoor department during a period of one year. Smears were prepared for Ziehl Neelsen stain and fluorescence stain both before and after homogenization and concentration procedure by $4 \% \mathrm{NAOH}-$ $2.9 \%$ sodium citrate method and results of them were interpreted according to RNTCP criteria for grading of sputum samples. All the samples were cultured in liquid culture MGIT system (Mycobacterial Growth Indicator Tube) and results of microscopy were compared with liquid culture taken as gold standard. Data were analyzed by using SPSS software version 16. Result: 350 samples were collected during study period. Out of 350 samples, 48 samples were positive for $M$. tuberculosis by MGIT system. In comparison with MGIT system, sensitivity of $Z \mathrm{~N}$ stain for detection of acid fast bacilli was $77 \%$ before decontamination procedure, which was increased up to $85.42 \%$ after decontamination and concentration process. Sensitivity of fluroscence stain was $85.42 \%$ before processing, which was increased up to $91.67 \%$ after processing of samples. Conclusion: Sensitivity of smear microscopy can be enhanced by use of fluroscence microscopy and concentration method.
\end{abstract}

\section{Keywords}

Ziehl-Neelsen Staining, Fluroscence Staining, 
Decontamination and Concentration Method

\section{Introduction}

Tuberculosis (TB) is a leading cause of morbidity and death worldwide, with approximately two billion people infected and approximately two million annual deaths attributable to it. In 2010, there were an estimated 8.8 million incident cases of TB globally, equivalent to 128 cases per 100,000 population, and an estimated 12.0 million prevalent cases of TB. This is equivalent to 178 cases per 100,000 population. Thus, approximately 1.4 million people died of TB in 2010 [1]. India accounts for nearly one third of global burden of tuberculosis, where diagnosis of tuberculosis relies mostly on smear microscopy method due to its simplicity, reliability, cost effectiveness and high specificity but its sensitivity is low in comparison with culture. It needs experienced person to screen the smear, it takes more time to screen negative smear, and it often misses the paucibacillary TB cases especially when the patient is co-infected with HIV [2].

Another microscopical technique which is available now is fluroscence staining, it is simpler and more rapid as it screens the smear in $40 \times$. This advantage would be more beneficial in overburden laboratories in low resource settings where culture facilities are not available. Even the cost of this microscopy method can be reduced by use of LED microscope instead of fluroscnece microscope which contains the bulb with life up to 50,000 hours [3].

Also processing of samples for decontamination and concentration method can also increase the sensitivity of $\mathrm{Z} \mathrm{N}$ stain and fluorescence stain as compared to direct smear preparation from slide.

The aim of this study was to compare both $\mathrm{Z} \mathrm{N}$ stain and fluorescence stain and also to compare the results of smears both before and after decontamination procedure.

\section{Material and Methods}

Study was planned after getting ethical approval for the same for one year period from newly registered suspected cases of tuberculosis from outdoor and indoor department of tertiary care hospital. From all the samples smears were prepared for $\mathrm{Z} \mathrm{N}$ and fluorescence stain using Carbol fuschin-phenol and Auramine phenol stain respectively. Then all the samples were processed for homogenization and concentration method by using $4 \% \mathrm{NAOH}-2.9 \%$ sodium citrate method. This process was done in biosafety cabinet with all personal protective measures. Equal volume of $4 \% \mathrm{NAOH}$ and $2.9 \%$ sodium citrate were mixed to make final concentration of $\mathrm{NAOH} 2 \%$. Samples which were collected in wide mouthed sterile container were transferred in to falcan collection tube of $50 \mathrm{ml}$ capacity, in to which equal amount as that of sample is added of mixture of $\mathrm{NAOH}$ and sodium citrate were added and tubes were left at for 20 minutes at room temperature. After which phosphate buffer solution ( $\mathrm{pH} 6.8,0.067 \mathrm{M}$ ) was added to neutralize the $\mathrm{pH}$ and then samples were centrifuged. Supernatant was discarded and in 
from deposit smear were prepared for $\mathrm{ZN}$ and flurochrome staining. Results of the smears were graded by RNTCP criteria for both the staining technique. Also all the samples were cultured in liquid culture MGIT system (Mycobacterial Growth Indicator Tube system). For which $800 \mu \mathrm{l}$ PANTA-OADC supplement is added in MGIT tube containing $7 \mathrm{ml}$ of Middlebrook $7 \mathrm{H} 9$ broth, then $500 \mu \mathrm{l}$ of processed sample was inoculated within 30 minutes with all aseptic precaution to reduce contamination and tubes were incubated in $37^{\circ} \mathrm{C}$ incubator and reading are taken daily in first 3 weeks and twice a week in next 3 weeks by using semi-automated MGIT reader (micro MGIT) which was standardize using Micro-MGIT caliber. Growth of $M$. tuberculosis was appear as granular turbidity while uniform turbidity suggest contamination which were again decontaminated and cultured in MGIT system. Positive MGIT tubes results were also confirmed by smear microscopy. Data were analyzed using SPSS software version 16.

\section{Result}

Out of 350 samples, 216 (61.71\%) were sputum samples, other samples were 115 (32.85\%) pleural fluid, 3(0.85\%) lymph node biopsy, 5 (1.42\%) ascetic fluid, 6 (1.71\%) CSF, $4(1.14 \%)$ pus and $1(0.28 \%)$ pericardial fluid. $256(73.14 \%)$ samples were from outpatient department. Direct smear microscopy result of all samples by $\mathrm{Z} \mathrm{N}$ stain had shown 37 (77.0\%) samples positive, out of which 4 were pleural fluid and 33 were sputum sample. While $41(85.41 \%)$ samples were positive by fluorescence staining method out of which 6 were pleural fluid and 35 were sputum sample. When both the methods were compared it had shown a statistically significance difference in rate of positivity by fluorescence staining when tested by fisher extract/mid P extract with $\mathrm{p}$ value $<0.05$.

Smear results after homogenization and concentration method by $\mathrm{Z} N$ stain had shown 41 (85.41\%) samples to be smear-positive out of which 6 were pleural fluid while 35 were sputum sample. while fluorescence stain had shown 44 (12.57\%) positivity out of which 7 were pleural fluid while 37 were sputum sample. When result of both the process was compared it had shown statistically significance difference when tested by fisher extract test with $\mathrm{p}$ value 0.05 . Smear which were missed by $\mathrm{Z} \mathrm{N}$ stain were mostly paucibacillary (smear grading with scanty or +1 ) with less bacterial load.

Out of 350 samples, 48 samples positive by MGIT. In comparison with liquid culture sensitivity of $\mathrm{ZN}$ stain was $77 \%$ which was increased by $85.92 \%$ after decontamination processing. Sensitivity of fluroscence stain was $85.92 \%$ before processing which is equal to sensitivity of $\mathrm{ZN}$ stain after processing. Sensitivity of fluorescence stain after processing is $91.67 \%$. Specificity of both staining technique is equal (98.55\%).

\section{Discussion}

In the present study we compared results of light microscopy by $\mathrm{Z} \mathrm{N}$ stain smear with that by fluorescent microscopy of auramine phenol stain smear for detection of AFB. These results shows fluorescence staining technique is more sensitive in detection of AFB in sputum as well as extra pulmonary samples compared to $\mathrm{ZN}$ stain. Smear result obtained by Githui et al. [4] had shown $80 \%$ by florescent microscopy $\& 65 \%$ by Z N 
staining; Ulukanligil et al. [5] also demonstrated $85.2 \%$ positivity by fluorescence microscopy and $67.6 \%$ by Z N method. Similar result obtained by S J Murry et al. [6] had shown $93 \%$ positivity by FI microscopy and $73 \%$ by $\mathrm{Z} \mathrm{N}$ staining. Jain et al. [7] had shown $41 \%$ by FI and $32 \%$ by $\mathrm{Z} \mathrm{N}$ stain.

All these results show that fluorochrome staining method is more sensitive as compared to $\mathrm{Z} \mathrm{N}$ staining method for demonstration of AFB. This may be due to appearance of brilliant yellow colored bacilli against more dark back ground which is easily observable.

Sputum smear microscopy is a simple, rapid and inexpensive technique which is highly specific in areas with a very high prevalence of tuberculosis. It also identifies the most infectious patients and is widely applicable in various populations with different socioeconomic levels. Hence, it has been an integral part of the global strategy for TB control [8].

In comparison with $\mathrm{Z} \mathrm{N}$ stain fluorescence microscopy which was introduce in 1930, requires the fluorochrome dye, halogen or high pressure mercury lamp to excite the dye. It is more sensitive in screening the low grade smear positive sputum samples and also extra pulmonary samples and samples from HIV patients as compared to $\mathrm{Z} \mathrm{N}$ staining. As it screens the smear in low power objectives, time require to screen the smear is less as compared to $\mathrm{ZN}$ stain which requires at least 10 - 15 minutes screening one negative smear, which is important in high burden countries like India with high work load. Cost constraints are major issues with fluorescent microscopy. This may be circumvented by the use of light emitting diodes (LEDs) which cost less than 10 per cent of a mercury vapor lamp. With a life $>50,000 \mathrm{~h}$, it can run on batteries and thus has been used in peripheral areas with definite operational advantages. Although sensitivity of fluorescence microscopy id 10 percent higher than $\mathrm{Z} \mathrm{N}$ stain, specificity is same as $\mathrm{ZN}$ stain and chances of false positivity are more in flurochrome stain while chances of false negativity are more with $\mathrm{Z} \mathrm{N}$ stain. Over all microscopy method results are affected by type of sample, quality and quantity of sample, thickness of smear, experience of observer and sensitivity is low in comparison to culture method and molecular method [8].

As Z N stain will be positive with bacterial load of $10^{5} / \mathrm{ml}$ and fluorochome $10^{4} / \mathrm{ml}$ of sample. So aim of this was to increase the of both the microscopy result especially in low grade positive smear and also in extra pulmonary sample with less bacterial load. Use of concentration method had yielded higher positivity of microscopy as compared to direct microscopy. This is due to concentration of sample, increase in number of bacilli per field as well as clean field without debris in which mycobacterial may be trapped sometimes. Any decontamination and concentration method can be used based on requirement. If we have to concentrate the sample only for smear microscopy then we can use the method that can kill the bacilli, so it can limit the laboratory infection. If have to do culture from processed sample then we have to use petroff's method or any method that will kill only contaminant bacilli and normal flora and that does not harm or damage the mycobacteria or its growth in culture medium either in liquid or on solid culture medium. Although its implication will depend on availability of biosafety 
cabinet, centrifuge, requires standardization of process. But still we can hope its implication for better management of patients [9] [10].

\section{Conclusion}

Sensitivity of smear microscopy for diagnosis of tuberculosis can be enhanced by use of fluorescence microscopy over light microscopy using ZN stain and concentration method which can help in diagnosis of tuberculosis. As it is cost effective, it can be applied for use in countries like India. LED microscope has made the use of fluorescence microscopy more convenient.

\section{Disclosure of Interest Statement}

The present study was funded from research funds of the authors. No pharmaceutical grants were used for this study.

\section{Ethical Clearance}

Approved by HREC committee of Government Medical College, Surat.

\section{References}

[1] Global Tuberculosis Control: WHO Report 2011. http://apps.who.int/iris/bitstream/10665/44728/1/9789241564380_eng.pdf

[2] Reider, H.L., Van Deun, A., Kam, K.M., Kim, S.J., Chonde, T.M., Trebucq, A., et al. (2007) Priorities for Tuberculosis Bacteriology Services in Low Income Countries. International Union against Tuberculosis and Lung Disease, The Union.

[3] Hooja, S., Pal, N., Malhotra, B., Goyal, S., Kumar, V. and Vyas, L. (2011) Comparison of Ziehl Neelsen \& Auramine O Staining Methods on Direct and Concentrated Smears in Clinical Specimens. Indian Journal of Tuberculosis, 58, 72-76.

[4] Githui, W., Kitui, F., Juma, E.S., Obwana, D.O., Mwai, J. and Kwamasga, D. (1993) A Comparative Study on the Reliability of Fuorooscnece Microscopy \& Ziehl-Neelsen Method in Diagnosis of Pulmonary Tuberculosis. East African Medical Journal, 70, 263-266.

[5] Ulukanligil, M., Aslan, G. and Tasci, S. (2000) A Comparative Study on the Different Staining Methods and Number of Specimens for Detection of Acid Fast Bacilli. Memórias do Instituto Oswaldo Cruz, 95, 55-58. https:/doi.org/10.1590/S0074-02762000000600019

[6] Murray, S.J., Barrett, A., Magee, J.G. and Freeman, R. (2003) Optimisation of Acid Fast Smears for the Direct Detection of Mycobacteria in Clinical Samples. Journal of Clinical Pathology, 56, 613-615. https:/doi.org/10.1136/jcp.56.8.613

[7] Jain, A., Bhargawa, A. and Agarwal, S.K. (2002) A Comparative Study of Two Commonly Used Staining Techniques for Acid Fast Bacilli in Clinical Specimens. Indian Journal of Tuberculosis, 49, 161.

[8] Desikan, P. (2013) Sputum Smear Microscopy in Tuberculosis: Is It Still Relevant? Indian Journal of Medical Research, 137, 442-444.

[9] Apers, L., Mutsvangwa, J., Magwenzi, J., Chigara, N., Butterworth, A., Mason, P. and Van der Stuyft, P. (2003) A Comparison of Direct Microscopy, the Concentration Method and the Mycobacteria Growth Indicator Tube for the Examination of Sputum for Acidfast Bacilli. International Journal of Tuberculosis and Lung Disease, 7, 376-381. 
[10] Kaore, N.M., Date1, K.P. and Thombare, V.R. (2011) Increased Sensitivity of Sputum Microscopy with Sodium Hypochlorite Concentration Technique: A Practical Experience at RNTCP Center. Lung India, 28, 17-20.

Submit or recommend next manuscript to SCIRP and we will provide best service for you:

Accepting pre-submission inquiries through Email, Facebook, LinkedIn, Twitter, etc. A wide selection of journals (inclusive of 9 subjects, more than 200 journals)

Providing 24-hour high-quality service

User-friendly online submission system

Fair and swift peer-review system

Efficient typesetting and proofreading procedure

Display of the result of downloads and visits, as well as the number of cited articles

Maximum dissemination of your research work

Submit your manuscript at: http://papersubmission.scirp.org/

Or contact aim@scirp.org 